[gw22-e0462] EFFECTS OF CONTINUE EXHAUSTIVE RUNNING ON RAT CARDIOVASCULAR ULTRASTRUCTURE, MYOCARDIAL APOPTOSIS AND VESSEL FUNCTION

Chen Fei Department of Physical Education, Hebei Normal University of Science, Hebei, China

10.1136/heartjnl-2011-300867.716

Objective To observe the effects of continue exhaustive running on rat cardiovascular ultrastructure, myocardial apoptosis and vessel function.

Methods Twenty four male Wistar rats were assigned to sedentary control group adaptive running group and continue exhaustive running group. After the end of running, the contraction and relaxation function of aortic vessels were assessed, the ultrastructure of myocardium and aorta was examined under transmission electron microscope. caspase-3, caspase-9 activity were measured, Myocardial cell apoptosis index was measured by flow cytometry, release of cytochrome $\mathrm{C}$ was determined by Western-blotting.

Results Compared with sedentary control group and adaptive running group, the aortic contraction response to phenylephrine was significantly depressed in continue exhaustive running group $(p<0.01)$. Lysis of aortic endothelium, break of internal elastic lamina. continue exhaustive running group were associated with significant increase of release of cytochrome $C$ and caspase- 3 , caspase- 9 activity $(p<0.05)$.

Conclusion Continue exhaustive running could lead to the impairment of vessel wall and myocardial mitochondria. The improvement in vessel relaxation and depression in contraction response may contribute to hypotension and sudden death after overexercise. 


\section{Correction: Effects of continue exhaustive running on rat cardiovascular ultrastructure, myocardial apoptosis and vessel function}

Fei C. Effects of continue exhaustive running on rat cardiovascular ultrastructure, myocardial apoptosis and vessel function. Heart 2011;97:A243.

Author name 'Fei Chen' is incorrect, it should be 'Fei Shen'.

(C) Author(s) (or their employer(s)) 2021. No commercial re-use. See rights and permissions. Published by BMJ.

Heart 2021;107:e5. doi:10.1136/heartjnl-2011-300867.716corr1

(A) Check for updates 